\title{
Statistical Analysis of the Influence of Financial Education Expenditure on Economic Growth in Shandong Province
}

\author{
Liu Jiwei \\ College of Quantitative and Technological Economics, University of Chinese Academy of Social Sciences, Beijing, China
}

Email address:

xunchanglu0901@163.com

\section{To cite this article:}

Liu Jiwei. Statistical Analysis of the Influence of Financial Education Expenditure on Economic Growth in Shandong Province. International Journal of Data Science and Analysis. Vol. 7, No. 2, 2021, pp. 39-50. doi: 10.11648/j.ijdsa.20210702.13

Received: January 14, 2021; Accepted: February 2, 2021; Published: April 26, 2021

\begin{abstract}
Education is a country's livelihood plan. It provides manpower and technology for development. The role of education in promoting the economy has been recognized by most countries, and the mutual influence of education and economic growth will increase with the improvement of the country's economic level. Obviously, the leading role of education in the economy has been valued by more countries. Shandong Province, being a big economic province is also a big province for college entrance examination, but there is still the problem of uneven distribution of economic resources. In order to make suggestions for the financial education expenditure in Shandong Province, it is of far-reaching significance to analyze the relationship between financial education expenditure and economic growth (gross regional product). Therefore, this article proposes two research questions. Question 1: Calculated on a per capita basis, is there a long-term equilibrium relationship among the four variables of fiscal education expenditure, scientific undertaking expenditure, total investment in fixed assets of the whole society, and gross regional product? To solve this problem, this article proposes two hypotheses. H0: There is no long-term equilibrium relationship between the four variables. H1: There is a long-term equilibrium relationship between the four variables. Question 2: On a per capita basis, what kind of work does fiscal education expenditure have on economic growth? To solve this problem, this paper proposes two hypotheses. H0: Fiscal education expenditures promote economic growth. H1: Financial education expenditure has a restraining effect on economic growth. In response to question 1, this paper uses Eivews to find a long-term equilibrium relationship between the four variables through the use of ADF test, E-G two-step method, and theoretical research. Aiming at problem 2, this paper uses Eviews software to establish an error correction model and finds that fiscal education expenditure has a promoting effect on economic growth, and for every increase of per capita fiscal education expenditure by one unit, the average per capita GDP increases by 6.688. And theoretical research also supports the results of data analysis. At the end of the article, policy recommendations for the development of financial education are put forward.
\end{abstract}

Keywords: Fiscal Education Expenditure, Gross Regional Product, Economic Growth, Long Term Equilibrium, Error Correction Model

\section{Introduction}

\subsection{Research Background}

Education is a major plan for people's livelihood, which provides human, technological and intellectual power for economic development. The development of education has always been the top priority of Shandong Province and the whole country. At the same time, education plays an important role in improving people's overall quality, narrowing regional economic differences, eliminating the gap between the rich and the poor, and building a harmonious and friendly society.
However, it is undeniable that the overall development of education in Shandong Province and even in China is still relatively backward, and there are still some problems such as unreasonable levels and insufficient allocation of educational resources. At the 19th National Congress of the Communist Party of China held in 2017, General Secretary Xi Jinping emphasized, "Giving priority to the development of education and building a strong education nation is the basic project for the great rejuvenation of the Chinese nation. Education must be given priority to accelerate the modernization of education and run the people Satisfactory education" [1]. To realize General Secretary Xi Jinping's expectation of education, that 
is, to organize the advancement of instruction, Shandong Province, in the current economic development, ought to guarantee that the improvement of education is put in financial turn of events. To start with, and monetary finances need to offer need to guaranteeing education speculation, and public assets to address the issues of schooling improvement.

With the year-on-year growth of Shandong's economic aggregate, the fiscal expenditure for education in 2019 exceeded 200 billion yuan [2]. Education is the essential efficiency of mechanical advancement and HR, and extending instruction speculation is fundamental for economic development. Notwithstanding, on account of restricted schooling \& education financing, Shandong Province has additionally since quite a while ago confronted the issue of lopsidedness and lacking instruction in the field. As the economic structural transformation enters a critical period and economic growth slows down, how the government can increase the spillover effect of education services by expanding the scale of education investment and further promote economic development has become an urgent issue. On the other hand, how to implement more effective fiscal education policies has become a new opportunity for economic crisis and transition period.

\subsection{Research Significance}

Because China has only entered the reform and opening up for more than 40 years, the current domestic research by scholars on the impact of fiscal education expenditure on economic growth is not perfect, and there are many different conclusions: some scholars believe that China fiscal education expenditure has promoted economic growth; others Scholars hold the opposite view. They believe that it has little effect on economic. Meanwhile, existing research mostly starts from the total amount and does not discuss these issues from the per capita perspective.

Therefore, this article hopes to do a more reasonable and comprehensive study on the impact of financial education expenditure on economic growth on the basis of previous scholars' research, so as to enrich the relevant literature. More important is to study whether the regional fiscal education expenditure contribute a significant impact to development of the regional economy. Therefore, this article attempts to statistically analyze the changes in the absolute scale and relative scale of Shandong province's financial education expenditures in recent years, as well as the development trend of economic growth. At the same time, based on the current educational economics and economic growth theories, the error correction model study the impact of Shandong province's fiscal education expenditure on economic growth. A correct analysis of the impact of financial education expenditure on economic growth has a bearing on national education, economic growth and the long-term development of society. It is also an important step to achieve the coordinated development of education and the economy. Therefore, analyzing the effect of fiscal education expenditure on growth of economic in Shandong province has important academic value and practical significance.

\subsection{The Main Content}

Chapter 1 of this article gives the research background and research significance.

Chapter 2 of this article gives a literature review.

Chapter 3 of this article gives the research method. This chapter contains General description, research questions and assumptions, research subjects, data sources, data analysis tools, and data limitations.

Chapter 4 of this article introduces the econometric terms involved.

Chapter 5 of this article introduces data analysis methods.

Chapter 6 of this article gives the research results of problems 1 and 2. This chapter contains data analysis results and evidence.

\section{Literature Review}

With the strategy of "Rejuvenating the Country through Science and Education", the importance of education has become more and more prominent, and the impact of education investment on social and economic growth has become more prominent. Many scholars have conducted an in-depth analysis of the long-term equilibrium and positive and negative effects.

Wang Ying's research uses China Statistical Yearbook and Jiangsu Provincial Statistical Yearbook to collect and sort out the time series data of investment in the field of education and economic growth from 1998 to 2017, and uses Douglas production function and econometric research methods to determine the relationship between fiscal education investment and economic growth in Jiangsu Province. Empirical research on the relationship between Jiangsu Province's fiscal education investment and economic growth maintains a long-term linear positive correlation. For every $1 \%$ increase in education expenditure, GDP increases by $0.7514 \%$ [3]. Based on the relevant data on education and economy in Hunan Province from 2000 to 2016, Zhu Jian used stationary test, Granger causality test, co-integration test and other measurement methods to empirically analyze the impact of Hunan Province's educational expenditure on economic growth. The empirical results demonstrate that in terms of economical increasing, Hunan's education fiscal expenditure plays a positive role, and there is a long-term equilibrium which related to four variables of fixed asset investment, number of employees, education fiscal expenditure, and Hunan GDP relationship [4]. Hui Letian uses the existing data of Yunnan Province's education fiscal expenditures, with the help of graph analysis and regression analysis, to use the public fiscal expenditures of elementary school, junior high school, high school, secondary vocational and higher education as research indicators, and conduct econometric measurement by years. The results obtained through data analysis and chart analysis pointed out the problems existing in the role of regional education fiscal expenditures at all levels in economic growth. And based on this, proposed reference suggestions on how regional education fiscal 
investment can promote steady economic growth in the future: improvement Investment direction, start a new mechanism, keep up with market demand, focus on skilled talents; rationally allocate funds and adjust the flow of funds, appropriate additional expenditures to achieve steady growth [5]. Ma Shuanyou studied the correlation between public education expenditure and economic growth, and believed that public education expenditure promotes economic development [6]. Wang Yanchao used OLS regression to conduct empirical analysis on the statistical data of China fiscal education expenditure and GDP from 1978 to 2004. His main argument is that fiscal education expenditure contributes significant positive impact to economic growth [7]. Zhang Zhinan tested the economic growth effects of different sources of education funding based on provincial panel data, and the results showed that education fiscal investment exert significant effect on improving the quality of economic growth [8].

From the present domestic research status, research achievements, scholars believe that education expenditure can promote economic growth. At the same time, in order to make the model more reasonable, scholars have also included scientific and technological funding, social investment and other control variables to improve the research. However, most of the research starts from the total research, and there is less research on the per capita situation. And there is also a lack of research based on the Shandong region, so this field needs further research and expansion.

\section{Research Method}

\subsection{General Description}

In order to study the long-term relationship between per capita financial education investment and per capita GRDP, this article uses data from the Shandong Provincial Bureau of Statistics for data analysis. [2]

\subsection{Research Questions and Hypotheses}

Question 1: Calculated on a per capita basis, whether there is a long-term equilibrium relationship among the financial education expenditures, scientific expenditures, total fixed asset investment of the whole society, and regional GDP, that is, whether there is a cointegration relationship among the four variables.

In response to this problem, this article sets the following two assumptions:

Null hypothesis (H0): There is no cointegration relationship between variables.

Alternative hypothesis (H1): There is a cointegration relationship between variables.

Question 2: What is the effect of fiscal education expenditure on economic growth?

Null hypothesis (H0): fiscal education expenditure has played a role in promoting economic growth, that is, as fiscal education expenditure increases, the regional GDP also rises.

Alternative Hypothesis (H1): Financial education expenditures hinder economic growth, that is, with the increase of financial education expenditures, the regional GDP declines.

\subsection{Research Subjects}

Shandong Province is a big economic province and an important source of college entrance examination candidates, so this article chooses Shandong Province as the research object.

In this paper, per capita gross regional product is taken as the explained variable, per capita financial expenditure on education is taken as the explanatory variable, per capita scientific expenditure and per capita total social fixed asset investment are taken as the control variable.

\subsection{Study Instruments}

CNKI (China National Knowledge Infrastructure) [9] and Baidu Scholar [10].

\subsection{Data Collection}

The data comes from the Statistical Yearbook of Shandong Provincial Bureau of Statistics. In view of the data published by the Shandong Provincial Statistics Bureau, the data time range is $1979-2019$.

\subsection{Data Analysis}

The software used for data analysis is Eviews and Excel.

\subsection{Limitations of the Study}

This statistical indicator is an annual statistic, so only the data from 1979 to 2019 is disclosed. The sample size is not particularly rich, but it can still meet the conditions for establishing a model.

\section{Basic Concept}

In order to better express the research, this article explains the econometric terms used. The following are several definitions:

\subsection{Long-term Equilibrium Relationship}

Assume that the long-term equilibrium relationship between $\mathrm{X}$ and $\mathrm{Y}$ is described as following:

$$
Y_{t}=a_{0}+a_{1} X_{t}+\mu_{t}
$$

$Y X_{t} a_{0} a_{1} \mu_{t}$ are the explained variable, explanatory variable, constant term, regression coefficient and random interference term (also called unbalanced error) of the time series respectively. This equilibrium relationship means that given a value of $\mathrm{X}$, the corresponding equilibrium value of $\mathrm{Y}$ is also determined as $a_{0}+a_{1} X_{t}$ [11]

It is worth noting that at the end of $\mathrm{t}-1$ period, there are one of three subordinate situations:

(i) $\mathrm{Y}$ is equal to its equilibrium value: $Y_{t-1}=a_{0}+a_{1} X_{t-1}$ 
(ii) $\mathrm{Y}$ is less than its equilibrium value: $Y_{t-1}<a_{0}+a_{1} X_{t-1}+\mu_{t}$

(iii) $\mathrm{Y}$ is greater than its equilibrium value: $Y_{t-1}>a_{0}+a_{1} X_{t-1}+\mu_{t}$

In period $\mathrm{t}$, assuming that $\mathrm{X}$ has a change $\Delta X_{t}$ ' if $\mathrm{X}$ and $\mathrm{Y}$ still satisfy their long-term equilibrium relationship at the periods' ending $\mathrm{t}$ and $\mathrm{t}-1$, then the corresponding change $\Delta Y_{t}$ of $\mathrm{Y}$ is given by the following formula:

$$
\Delta Y_{t}=a_{1} \Delta X_{t}+v_{t}
$$

Among them, $v_{t}=\mu_{t}-\mu_{t-1}$ in the equation.

\subsection{Single Integer}

Single integer is a way to deal with the problem of false regression. ${ }^{11}$ If a time series becomes stationary after one difference, then the original series is called a single integer of order 1, denoted as I (1). In general, if the time series becomes a stationary series after $\mathrm{d}$ difference, but it is still not stationary after d-1 difference, then the original series is called a single integer series of order d, denoted as I (d). [11]

\subsection{Cointegration}

When the time series $\{\mathrm{x}\}$ and $\{\mathrm{y}\}$ of the two variables are the same order single integer sequence, that is, I (d), can there be a cointegration relationship. ${ }^{11}$ When long-term equilibrium relationship between variables can be established, it indicates that the unbalanced error sequence is an I (0) sequence, and the relationship between variables is said to be cointegrated.

\section{Data Analysis Method and Its Definition}

For question 1, the test of long-term equilibrium relationship between variables, that is, the test of whether the relationship between variables is cointegrated, requires the following econometric methods:

\subsection{Single integer Test}

Named unit root test [12], commonly used method is ADF inspection. The single integral order of each variable is detected to facilitate the subsequent determination of the cointegration relationship. ADF inspection method: For time series $\{\mathrm{X}\}, \mathrm{ADF}$ test is done by three models [13].

(i) Model 1: $\Delta X_{t}=\delta X_{t-1}+\sum_{i=1}^{m} \Delta X_{t-i}+\varepsilon_{t}$

(ii) Model 2: $\Delta X_{t}=\alpha+\delta X_{t-1}+\sum_{i=1}^{m} \Delta X_{t-i}+\varepsilon_{t}$

(iii) Model 3: $\Delta X_{t}=\alpha+\beta t+\delta X_{t-1}+\sum_{i=1}^{m} \Delta X_{t-i}+\varepsilon_{t}$

Symbol $t$ in Model 3 is variable of time, which represents a certain trend of the time series over time. And ADF test's null hypothesis H0: $\delta=0$, i.e., there is a unit root. The actual test starts with model 3 , then model 2 , and finally model 1 . When to test the rejection of the null hypothesis, i.e., when the original sequence does not have a unit root which called stationary sequence, when can the test be stopped. Otherwise, it is need to continue the test until the model 1 is tested. This paper adopts the Modified Hannan-Quinn Lag length automatic selection criterion to determine the lag term $\mathrm{m}$.

\subsection{Cointegration Test}

The test of the co-integration relationship of variables can be carried out through the graphical method and the E-G two-step method. The E-G two-step method includes the ADF method of unit root test. Therefore, the method steps are as follows [14]:

Preparatory work: Preliminarily judge whether the trends between variables are similar through the graphical method, and then judge whether it is a single integration of the same order through the result of the single integration test.

E-G two-step method: Engle-Granger test, to judge whether there is the relationship of cointegration situation between single integer variables of the same order. The specific content is as follows, assuming there are 4 variables, $\mathrm{Y}, \mathrm{X} 1, \mathrm{X} 2, \mathrm{X} 3$, first perform the following least squares estimation:

$$
Y_{t}=\beta_{0}+\beta_{1} \cdot X_{1 t}+\beta_{2} \cdot X_{2 t}+\beta_{3} \cdot X_{3 t}+\mu_{t}
$$

After obtaining estimated value of each parameter $\hat{\beta}_{i}(i=0,1,2,3)$, the residual term is calculated by the following equation:

$$
\hat{e}_{t}=Y_{t}-\left(\hat{\beta}_{0}+\hat{\beta}_{1} \cdot X_{1 t}+\hat{\beta}_{2} \cdot X_{2 t}+\hat{\beta}_{3} \cdot X_{3 t}\right)
$$

Then the single-integration test is performed on the obtained residual sequence $\left\{\hat{e}_{t}\right\}$.

If it is an I (0) sequence, the above four variables have a long-term equilibrium relationship, that is, they are called cointegration.

For question 2, if the variables satisfy the co-integration relationship, for the better analyze and research the influence of variables on the growth of economic, this paper establishes an error correction model (ECM). The definition of ECM is given below for subsequent analysis.

\subsection{The Error Correction Model (ECM)}

The ECM is an econometric model with a specific form, whose main form is proposed by Davidson, et al, in 1978, also known as the DHSY model. To facilitate subsequent analysis, this section introduces its structure through a specific model.

Definition of ECM [15]: Assume that the long-term equilibrium relationship between the two variables $\mathrm{X}$ and $\mathrm{Y}$ is shown in $Y_{t}=a_{0}+a_{1} X_{t}+\mu_{t}$. Since $\mathrm{X}$ and $\mathrm{Y}$ are rarely at equilibrium in the real economy, what is actually observed is only the short-term NOR between $\mathrm{X}$ and Y. A balanced relationship, assuming the following $(1,1)$ order distributed lag form: ${ }^{14}$ 


$$
Y_{t}=\beta_{0}+\beta_{1} X_{t}+\beta_{2} X_{t-1}+\delta Y_{t-1}+\mu_{t}
$$

The model shows that the $\mathrm{Y}$ value in the $\mathrm{t}$ period is not only related to the change of $\mathrm{X}$, but also related to the state values of $\mathrm{X}$ and $\mathrm{Y}$ in the $\mathrm{t}-1$ period. Since the variables may be non-stationary, ordinary least squares cannot be used directly. Deform the above formula to get:

$$
\begin{aligned}
\Delta Y_{t} & =\beta_{0}+\beta_{1} \Delta X_{t}+\left(\beta_{1}+\beta_{2}\right) X_{t-1}-(1-\delta) Y_{t-1}+\mu_{t} \\
& =\beta_{1} \Delta X_{t}-(1-\delta)\left(Y_{t-1}-\frac{\beta_{0}}{1-\delta}-\frac{\beta_{1}+\beta_{2}}{1-\delta} X_{t-1}\right)+\mu_{t} \\
& =\beta_{1} \Delta X_{t}-\lambda\left(Y_{t-1}-\alpha_{0}-\alpha_{1} X_{t-1}\right)+\mu_{t}
\end{aligned}
$$

$$
\text { And } \lambda=1-\delta, \alpha_{0}=\frac{\beta_{0}}{1-\delta}, \alpha_{1}=\frac{\beta_{1}+\beta_{2}}{1-\delta} \text {. }
$$

The term in brackets is the unbalanced error term in t-1 period. So formula which given above illustrates that the change of $\mathrm{Y}$ is determined by the change of $\mathrm{X}$ and the degree of imbalance in the previous period. At the same time, this formula also makes up for the shortcomings of simple difference, because it contains the degree of pre-imbalance expressed by X, Y level values. Therefore, the value of $\mathrm{Y}$ has corrected the degree of imbalance in the previous period. This formula is called the first-order error correction model and can be further rewritten as: $[14,15]$

$$
\Delta Y_{t}=\beta_{1} \Delta X_{t}-\lambda e c m_{t-1}+\mu_{t}
$$

Where ecm represents the error correction term. The regression coefficient can be obtained by performing ordinary least squares estimation on the above formula.

If the cointegration relationship is not satisfied, then use the OLS model and Pearson correlation test to determine whether the explanatory variable is significant.

\section{Research Results}

First of all, in order to facilitate the description and expression of the formula below, the symbols of the used variables are given here.

Table 1. Variables and their symbols.

\begin{tabular}{ll}
\hline Variables & Symbols \\
\hline Per Capita GRDP (Ten thousand yuan) & Y \\
Per Capita Fiscal Expenditure on Education (Ten thousand yuan) & X1 \\
Scientific Expenses (Ten thousand yuan) & X2 \\
Per Capita Total Fixed Asset Investment (Ten thousand yuan) & X3 \\
\hline
\end{tabular}

Since the Shandong Provincial Bureau of Statistics publishes total data, this article obtains total population data from the statistical yearbook, and averages the total data per capita.

The results after processing are shown below.

Table 2. Variables after data preprocessing.

\begin{tabular}{lllll}
\hline Year & Y & X1 & X2 & X3 \\
\hline 1979 & 347.898 & 5.956 & 0.573 & 57.895 \\
1980 & 400.397 & 7.305 & 0.556 & 84.087 \\
\hline
\end{tabular}

\begin{tabular}{lllll}
\hline Year & Y & X1 & X2 & X3 \\
\hline 1981 & 468.654 & 7.363 & 0.554 & 94.618 \\
1982 & 527.595 & 8.381 & 0.578 & 106.218 \\
1983 & 607.919 & 8.944 & 0.666 & 112.374 \\
1984 & 761.503 & 10.152 & 0.882 & 126.306 \\
1985 & 884.288 & 12.679 & 0.846 & 182.131 \\
1986 & 954.282 & 14.758 & 1.036 & 249.910 \\
1987 & 1131.056 & 15.904 & 0.894 & 282.773 \\
1988 & 1395.505 & 20.213 & 1.274 & 371.794 \\
1989 & 1581.640 & 22.967 & 1.288 & 452.047 \\
1990 & 1793.910 & 23.986 & 1.382 & 362.702 \\
1991 & 2121.561 & 26.379 & 1.495 & 393.321 \\
1992 & 2560.058 & 31.664 & 1.705 & 512.611 \\
1993 & 3213.886 & 39.101 & 1.935 & 697.796 \\
1994 & 4442.968 & 53.661 & 2.582 & 1031.411 \\
1995 & 5692.851 & 60.195 & 2.592 & 1273.417 \\
1996 & 6726.649 & 76.680 & 3.116 & 1510.198 \\
1997 & 9599.222 & 110.628 & 5.136 & 2287.827 \\
1998 & 7914.055 & 99.888 & 4.024 & 2020.086 \\
1999 & 8399.283 & 112.072 & 3.978 & 2305.503 \\
2000 & 9223.465 & 131.592 & 4.294 & 2475.955 \\
2001 & 10057.868 & 152.652 & 5.034 & 2817.653 \\
2002 & 11110.949 & 179.486 & 5.850 & 3096.030 \\
2003 & 11971.047 & 196.693 & 6.409 & 3852.975 \\
2004 & 14523.715 & 223.539 & 7.200 & 5815.170 \\
2005 & 17311.659 & 270.026 & 8.301 & 8281.633 \\
2006 & 20435.036 & 314.893 & 9.755 & 11357.326 \\
2007 & 24307.789 & 485.082 & 49.655 & 11915.322 \\
2008 & 28860.967 & 586.662 & 60.832 & 13348.616 \\
2009 & 31263.414 & 649.261 & 66.545 & 16336.046 \\
2010 & 35573.081 & 807.935 & 88.469 & 19956.974 \\
2011 & 40730.821 & 1092.585 & 113.248 & 24269.305 \\
2012 & 44840.616 & 1369.312 & 130.454 & 27943.351 \\
2013 & 49255.441 & 1456.171 & 155.157 & 32517.645 \\
2014 & 52092.788 & 1498.972 & 150.874 & 37743.993 \\
2015 & 56290.766 & 1721.262 & 161.935 & 43265.679 \\
2016 & 59230.380 & 1840.530 & 168.330 & 53747.092 \\
2017 & 62955.440 & 1888.298 & 195.596 & 55153.092 \\
2018 & 66015.125 & 1987.423 & 230.526 & 56919.614 \\
2019 & 70031.070 & 2124.690 & 301.296 & 51871.201 \\
\hline & & & & \\
& & & & \\
\hline & & & & \\
& & & &
\end{tabular}

\subsection{Question 1}

Calculated on a per capita basis, whether there is a long-term equilibrium relationship among the financial education expenditures, scientific expenditures, total fixed asset investment of the whole society, and regional GDP (GRDP), that is, whether there is a cointegration relationship among the four variables.

In response to this problem, this article sets the following two assumptions:

Null hypothesis (H0): There is no cointegration relationship between variables.

Alternative hypothesis (H1): There is a cointegration relationship between variables.

Independent variables: per capita financial education expenditure (X1), per capita scientific undertaking expenses (X2), per capita total social fixed asset investment (X3).

Dependent variable: per capita GRDP (Y)

The purpose of this question is to study whether there is a long-term equilibrium relationship (cointegration) between dependent variable and the independent variable, so as to improve the theory which related to relationship between educational investment and economic in period of long-term. 
This article also selects two other independent variables as control variables to obtain results that are more in line with the actual economic conditions. The analysis about long-term relationships will not only help improve economic theory, but also help formulate fiscal policy.

$\mathrm{H} 1$ : There is a cointegration relationship between variables.

Data analysis results (i): Firstly, use the graphical method for the four selected variables to make a preliminary judgment of the long-term development trend. The result is as follows:

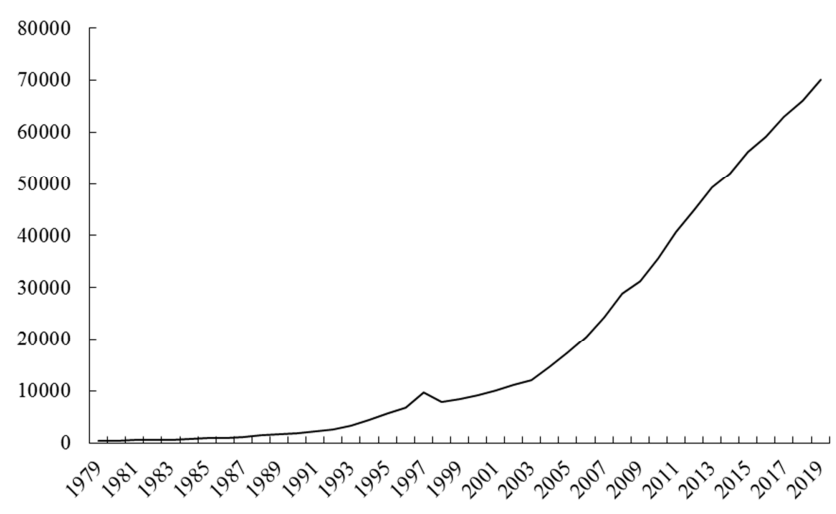

Figure 1. Development trend line chart of per capita GRDP (Y).

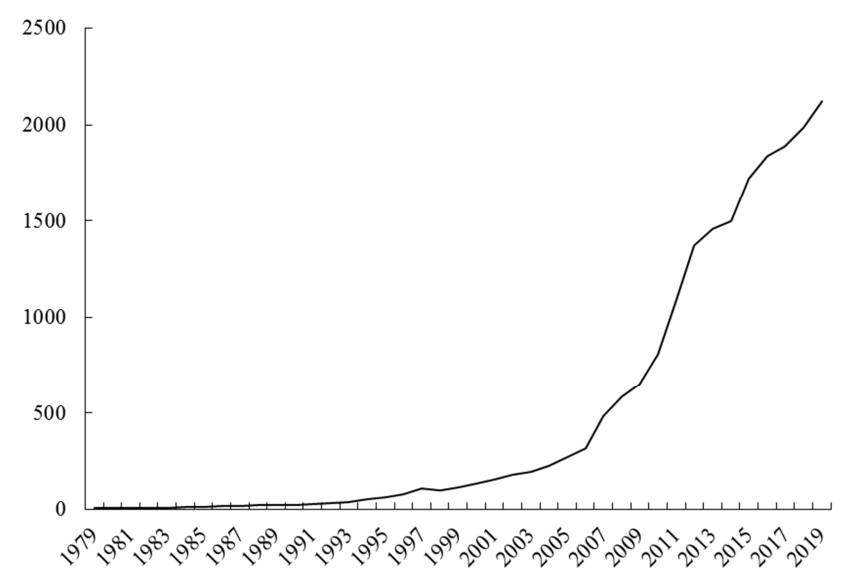

Figure 2. Development trend line chart of per capita financial education expenditure $(X 1)$.

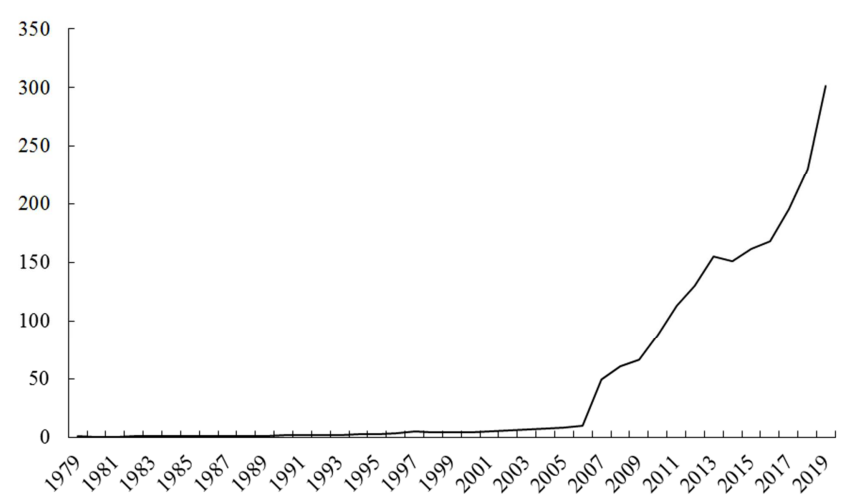

Figure 3. Development trend line chart of per capita scientific undertaking expenses (X2).

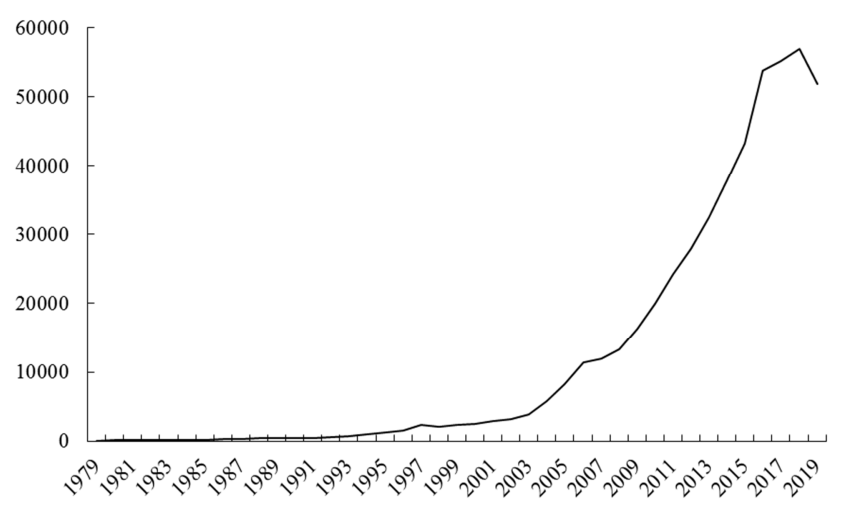

Figure 4. Development trend line chart of per capita total social fixed asset investment $(X 3)$.

The development trend line chart of the four variables is shown above. Looking at the overall trend, all four have shown an upward trend. Except for the slight decline in the total fixed asset investment of the whole society in 2018-2019, the other three variables have shown an increasing development trend from 1979 to 2019. Moreover, the growth rate is gradually accelerating. Specifically, starting in 2005, the development speed of the four variables has increased sharply. This also shows that the development trends among the four variables are similar. Therefore, this article preliminarily judges that there may be a long-term equilibrium relationship between the four variables. To further analyze whether the long-term equilibrium relationship (i.e. cointegration) holds, this paper conducts a more in-depth data analysis on the four variables.

Data analysis results (ii): The premise of the multivariate cointegration relationship is to satisfy the same order single integration, so this article uses ADF test to test each variable one by one, ADF (Augmented Dickey-Fuller test statistic). The test results are shown:

As shown in the table, in the 0th and 1st order difference, the four variable models fail the test, that is, they must not be single integers of order 0 and order 1 . Therefore, this paper conducts the ADF test for the second difference. The Y, X1, and X2 variables are tested using Model 3, and in the second-order difference, the $\mathrm{P}$ values corresponding to the ADF test statistics are all less than 0.05 , that is, the three variables are all second-order single integers. The $\mathrm{X} 3$ variable is tested using Model 1, and the P value corresponding to the ADF test statistic is 0.0096 , which is less than 0.05 , so this variable is also a second-order single integer.

Table 3. The result of ADF test.

\begin{tabular}{lllll}
\hline Variable & ADF Model & ADF Statistics & P-value & Order \\
\hline Y & Model3 & 0.711 & 1.000 & 0 \\
& Model2 & 0.289 & 0.975 & 0 \\
& Model1 & 0.250 & 0.753 & 0 \\
& Model3 & -2.074 & 0.543 & 1 \\
& Model2 & -0.813 & 0.804 & 1 \\
& Model1 & -0.061 & 0.656 & 1 \\
& Model3 & -11.199 & 0.000 & 2 \\
& Model3 & 0.294 & 0.998 & 0 \\
& Model2 & -0.155 & 0.936 & 0 \\
& Model1 & -0.034 & 0.665 & 0 \\
\hline
\end{tabular}




\begin{tabular}{lllll}
\hline Variable & ADF Model & ADF Statistics & P-value & Order \\
\hline \multirow{4}{*}{ X2 2} & Model3 & -2.059 & 0.551 & 1 \\
& Model2 & -1.185 & 0.671 & 1 \\
& Model1 & -0.531 & 0.480 & 1 \\
& Model3 & -6.403 & 0.000 & 2 \\
& Model3 & 2.106 & 1.000 & 0 \\
& Model2 & 2.695 & 1.000 & 0 \\
& Model1 & 2.860 & 0.999 & 0 \\
& Model3 & 0.347 & 0.998 & 1 \\
& Model2 & 0.278 & 0.974 & 1 \\
& Model1 & -0.322 & 0.563 & 1 \\
X3 & Model3 & -7.870 & 0.000 & 2 \\
& Model3 & -0.309 & 0.987 & 0 \\
& Model2 & -0.892 & 0.780 & 0 \\
& Model1 & -0.662 & 0.424 & 0 \\
& Model3 & -0.369 & 0.984 & 1 \\
& Model2 & -0.666 & 0.842 & 1 \\
& Model1 & -0.148 & 0.626 & 1 \\
& Model3 & -2.670 & 0.254 & 2 \\
& Model2 & -2.595 & 0.103 & 2 \\
& Model1 & -2.646 & 0.010 & 2 \\
\hline
\end{tabular}

According to the E-G two-step method, when the selected variables meet the same order single integers, the residuals of the ordinary least squares regression need to be tested for unit roots. If the residual sequence is full of order 0 single integers, the selected variables have a cointegration relationship. The residual sequence obtained after ordinary least square regression of $\mathrm{Y}$ and $\mathrm{X} 1, \mathrm{X} 2, \mathrm{X} 3$ in this paper is as follows:

Table 4. The result of ecm.

\begin{tabular}{ll}
\hline Year & ecm \\
\hline 1979 & -2963.219 \\
1980 & -2963.971 \\
1981 & -2897.090 \\
1982 & -2877.263 \\
1983 & -2814.715 \\
1984 & -2697.641 \\
1985 & -2674.186 \\
1986 & -2671.800 \\
1987 & -2545.916 \\
1988 & -2428.096 \\
1989 & -2345.232 \\
1990 & -2179.783 \\
1991 & -1940.907 \\
1992 & -1694.733 \\
1993 & -1313.063 \\
1994 & -609.594 \\
1995 & 399.887 \\
1996 & 811.646 \\
1997 & 2485.900 \\
1998 & 1152.241 \\
1999 & 1167.087 \\
2000 & 1226.154 \\
2001 & 1274.063 \\
2002 & 1300.595 \\
2003 & 1569.326 \\
2004 & 3282.834 \\
2005 & 4498.726 \\
2006 & 6203.760 \\
2007 & 5277.981 \\
2008 & 6418.227 \\
2009 & 6891.366 \\
2010 & 6262.679 \\
2011 & 1541.788 \\
2012 & -4376.546 \\
\hline & \\
\hline
\end{tabular}

\begin{tabular}{ll}
\hline Year & ecm \\
\hline 2013 & -1697.877 \\
2014 & -257.708 \\
2015 & -3973.254 \\
2016 & -4410.280 \\
2017 & -1036.735 \\
2018 & 12.099 \\
2019 & 1593.250 \\
\hline
\end{tabular}

The results of the ADF test with a lag order of 3 on the residual sequence are as follows:

Table 5. The result of ADF test based on ecm.

\begin{tabular}{lllll}
\hline Variable & ADF model & ADF statistics & P value & Order \\
\hline ecm & Model 3 & -2.178921 & 0.03 & 0 \\
\hline
\end{tabular}

The results show that in model 3, the residual sequence ecm passed the 0 -order ADF test, where the ADF test statistic is -2.179 , and the p-value is 0.05 and less than 0.05 . The null-hypothesis is rejected, that is, the residual sequence is stationary, i,e, there is a cointegration relationship between $\mathrm{Y}$, $\mathrm{X} 1, \mathrm{X} 2, \mathrm{X} 3$ variables.

So far, this article has verified the cointegration relationship between variables through two different data analysis methods.

\subsection{Question 2}

Question 2: What is the effect of per capita fiscal education expenditure on economic growth?

H0: Financial education expenditures hinder economic growth, that is, with the increase of per capita financial education expenditures, the per capita regional GDP declines.

H1: fiscal education expenditure has played a role in promoting economic growth, that is, as per capita fiscal education expenditure increases, the per capita regional GDP also rises.

The purpose of research question 2 is to correctly understand the effect of per capita financial education expenditure on per capita GRPD. The essence of this question is to study the significance of education to economic development. If education plays a positive role in promoting economic development, then the financial sector should support the policy of fiscal education support.

$\mathrm{H} 1$ : fiscal education expenditure has played a role in promoting economic growth, that is, as fiscal education expenditure increases, the regional GDP also rises.

Data analysis results (i): First of all, through the study of question 1, this paper obtains the result that the variables are cointegration. Therefore, this article can further analyze the significance of education to economic growth by establishing an ECM. The error correction model established in this paper is as follows:

$$
\Delta Y_{t}=\beta_{1} \Delta X_{1 t}+\beta_{2} \Delta X_{2 t}+\beta_{3} \Delta X_{3 t}-\lambda e c m_{t-1}+\mu_{t}
$$

Where ecm is the residual sequence obtained in question 1 , that is, ecm $t=Y_{t}-\hat{\beta}_{1} X_{1 t}+\hat{\beta}_{2} X_{2 t}+\hat{\beta}_{3} X_{3 t}$

The model is estimated by OLS. 
Results obtained are shown in the following table:

Table 6. OLS estimation results of ECM.

\begin{tabular}{llll}
\hline Variable & Coefficient & t-Statistic & Prob. \\
\hline$\Delta X_{1 t}$ & 6.686 & 1.716 & 0.095 \\
$\Delta X_{2 t}$ & 70.122 & 4.419 & 0.001 \\
$\Delta X_{3 t}$ & 0.375 & 4.302 & 0.001 \\
$e c m_{t-1}$ & 0.068 & 1.267 & 0.214 \\
\hline
\end{tabular}

From the results, the t-test statistic of $\mathrm{X} 1$ is 1.716 , and the $\mathrm{p}$ value is 0.095 , so this variable is still significant at the 0.1 confidence level. The table shows that the coefficient of this variable is 6.686 , which means that for every unit increase in this variable, $\mathrm{Y}$ increases by 6.686 on average. That is, increasing investment in education can promote economic growth.

Data analysis result (II): Secondly, according to the trend analysis of the line chart in Chapter VI, this article already knows that $\mathrm{Y}$ and $\mathrm{X} 1$ are approximate trends. Further, make a scatter plot between two variables.

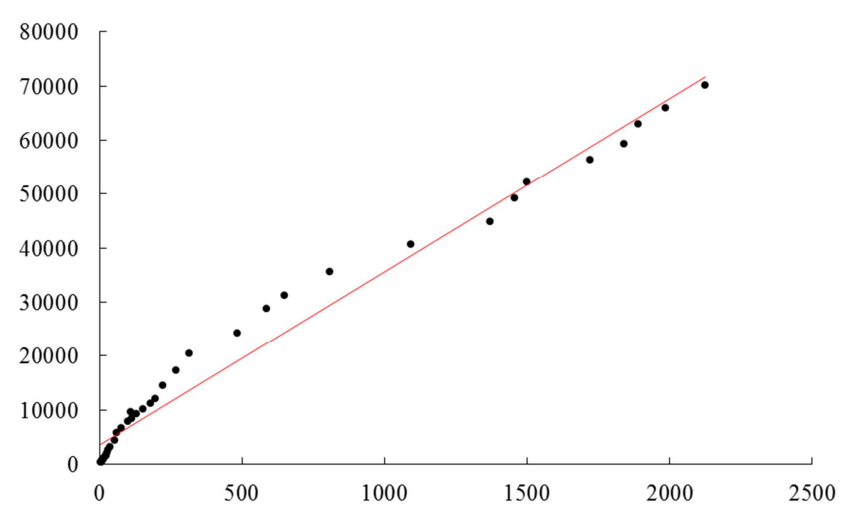

Figure 5. Per capita fiscal expenditure on education (X1) and per capita GRDP (Y) scatter plot.

It can be found from the image that the two are positively correlated, and $\mathrm{Y}$ also increases with the increase of $\mathrm{X}$. To further verify the correlation between the two, this paper conducted a Pearson correlation test on the two variables, and the results are as follows

Table 7. Pearson correlation coefficient.

\begin{tabular}{lll}
\hline & X1 & Y \\
\hline $\mathrm{X} 1$ & 1 & 0.989 \\
$\mathrm{Y}$ & 0.989 & 1 \\
\hline
\end{tabular}

The results show that the $\mathrm{X} 1 \& \mathrm{Y}$ correlation coefficient reaches 0.989 , which is very high. The graph and analysis also show that financial education investment promotes economic development. It should be noted that data analysis (ii) is only used as a supplement to data analysis (i), because data analysis I starts from the perspective of causality, and has complete construction steps, which is more reliable.

\section{Discussion}

For, questiton 1, there's a couple of evidence.

Evidence (i):

(1) Sun He studied the relationship between finance and tax education and economical growth in Yunnan, and considered that education development was beneficial to economic development. He believes that the impact of investment in education on economic growth is much greater than that of capital investment. At the present stage of economic development in Yunnan, it is imperative to strengthen education at the secondary and higher levels to meet the upgrading of the economic structure [16]. (2) Wang Yuhong used human capital theory and economic growth theory as the theoretical basis, combined with relevant theories about the relationship between regional economic growth and higher education development, and used time series data from 1980 - 2006 for empirically demonstration of the relationship between economic growth and higher education development in Jiangxi test. He used the co-integration test, Granger causality model, and error correction model to empirically test the relationship between the quantitative growth, quality improvement and economic growth of Jiangxi higher education development. Finally, from the structure and benefit of Jiangxi higher education development Study the relationship between Jiangxi higher education and economic growth. After empirical research, it is concluded that there is a long-term equilibrium relationship between Jiangxi higher education development and economic growth [17]. (3) Jiang Minghui used unit root test, Granger causality test and ECM to carry out analysis on the relationship between education investment and economic growth in Shandong Province from 1979 to 2004. Research shows that education investment in Shandong Province, i.e., there is a one-way causal relationship with economic growth, and there is a stable long-term equilibrium relationship of synergy and interaction [18].

Evidence (ii):

According to macroeconomic theory, education belongs to total factor productivity, which is derived from production function. Therefore, education and economic growth maintain a dynamic relationship. At the same time, the production function can provide a long-term description of macroeconomic growth. Therefore, the dynamic relationship between education comsuption and the increasing and growth of economic is actually long-term.

H0: There is no cointegration relationship between variables.

Data analysis result: According to the results of data analysis done about $\mathrm{H} 1$, the $\mathrm{H} 0$ viewpoint is not supported.

Evidence (i): Financial education expenditure consumes a lot of finances, but education income has not increased sharply. Talents need to be cultivated for a period of time, which has caused effect of education expenditure on economy to be delayed. Therefore, the long-term relationship between fiscal education investment and economic growth is difficult to stabilize, that is, there is no long-term equilibrium relationship. 
Comparison: Judging from the results of data analysis and the evidence cited: the results of data analysis, whether it is graphical or test method, support the long-term equilibrium relationship between per capita fiscal education expenditure and GRPD, that is, there is a long-term equilibrium relationship between education expenditure and economic growth. But for $\mathrm{H} 0$, almost no scholars have made assumptions about the imbalance between education and economic growth. Moreover, data analysis results in this chapter do not support $\mathrm{H} 0$ at all.

Taking into account economic development, people are the main factor, and education is what determines the potential of people. That's why there are the terms "a century-old plan, education-oriented" and "science and technology are the primary productive forces". People with good quality are the key factors for economic development. Therefore, fiscal education expenditure and economic growth are in long-term equilibrium. That is, $\mathrm{H} 1$ is valid.

For, questiton 2, there's a couple of evidence.

Evidence (i):

In macroeconomic theory, production functions are usually used to study various economic activities related to economic growth. The macro production function uses a functional form to ingeniously link the material output of an economic activity with the input of production factors and technological status. The most commonly used macro production function is the Cobb-Douglas production function. In 1928, Cobb and Douglas derived following production function, which described the relationship between physical capital, labor, and output:

$$
Q=a K^{b} L^{c}
$$

Among them, $\mathrm{Q}$ is output, $\mathrm{K}$ is physical capital investment, and $\mathrm{L}$ is the number of employees. $\mathrm{a}, \mathrm{b}$, and $\mathrm{c}$ are constants, and the range of $b$ and $c$ is $(0,1)[19]$. Their discovery proved to be robust. Among them, a often represents the level of technology and human capital that are difficult to calculate. The level of science and technology and human capital are inseparable from fiscal education expenditures. Therefore, this is also an evidence that fiscal education expenditures promote economic development.

Evidence (ii): (1) Education is an important source of industrial economic growth. Under the social background of building a socialist innovation-oriented country, we can deeply realize that the important role of education in promoting economic development is of great significance to the development of the overall national strength of the entire country. Judging from the development history of our country and the development history of developed countries, we can find the effective promotion and important contribution of education to economic growth. Technological changes often play a role in promoting the leaping growth of the national economy in the process of national economic development. The key factor for technological change lies in the cultivation of talents. The cultivation of talents directly depends on education, so the importance of education can be achieved. It clearly highlights that it can not only impart a wealth of scientific knowledge, but also create a steady stream of new knowledge [20]. (2) Education can effectively improve the quality of workers. To a certain extent, the driving force of economic growth comes from the quality of the labor force. The level of education of the labor force determines the level of knowledge and skills of the laborers. The higher the education level of the laborers, the more advanced knowledge and labor skills they master., The higher the labor productivity. Until now, the world's major multinational companies have two important prerequisites when investing in countries around the world. One is whether the investment policies of the local government are favorable. The other is whether the local personnel have high cultural qualities. The second condition is often an important factor in investment choices in high-tech industries. Therefore, those Western European countries have become investment hotspots for multinational companies because of their high-quality education and labor quality.

Evidence (iii) (1) Education can effectively facilitate the industrial structure adjustment. The formation and development of industries will be influenced by many factors. Education is one of the most significant decisive factors, which can promote rapid economic growth through its impact on the industrial structure. Specifically, it's mainly manifested in two aspects: one is that education plays an important role in refinement, development and deepening of social division of labor, which is also the main prerequisite for the development of industrial structure. Impacts include labor means, labor, and labor objects, and the changes in these factors of productivity are precisely the basis for the macroscopic changes in the social production ratio. With the continuous development of social productivity and constantly updated educational concepts, people are more and more aware of the importance of education, and the investment in current education is far less than the economic and social benefits obtained in future production [21, 22]. (2) And more importantly, education effectively increases labor productivity. The increase in labor productivity is closely related to the level of education and cultural quality of workers. According to the clear results researched by scholars in related fields in China, workers of different cultural levels have different effects on improving labor productivity: $43 \%$ in primary schools, $108 \%$ in middle schools, and $300 \%$ in universities [23]. According to the results of practical surveys, workers with higher education play a significantly higher role in technology, management, and creativity than those with lower education. The continuous development of science and technology can effectively promote the upgrading of products and improve the quality of products, thereby realizing goal of improving product quality, reducing costs, and increasing income, and promote the subsequent expansion of reproduction.

Evidence (IV) Economic development needs education first. The development of the economy requires the advancement of education, which means that in order to promote the further development of the economy under premise of certain productivity development, the development of education is a 
necessary condition [24]. Advanced education means that growth rate of investment in education is much higher than the growth rate in economy; in terms of cultivating talents, not only the short-term economic construction needs should be considered, but also the long-term development needs should be taken into account, and forward goals should be set. An outstanding feature of education is that it is futuristic. The purpose of education is to cultivate talents for the future society, and it has a long period of time. The knowledge in modern society is updated very quickly, which objectively requires that the training and education of talents must be earlier than economic development. Long-term practice has strongly proved that when the development speed of education is ahead of the economic development speed, education will promote the development of social productivity and social economy; on the contrary, when the development of education lags behind needs from social and economic development, it will Seriously hinder the further development of productivity. From the many practical experiences of economical development in various developed countries and regions, it can be seen that they have always attached great importance to investment in education, especially in the development of population intelligence. Taking the lead in developing education is necessary guarantee for rapid developments related social and economic.

Comprehensive data analysis and evidence, fiscal education expenditure can effectively promote economic development.

H0: Financial education expenditures hinder economic growth, that is, with the increase of financial education expenditures, the regional GDP declines.

Data analysis result: Judging from the data analysis results in part H1, fiscal education expenditure does not hinder economic development. Therefore, the data analysis results in this article do not support this hypothesis.

Evidence (i): Li Yining believes that the amount of funds a country may use for the development of education is ultimately restricted by its own financial resources. The scale and speed of the development of education should be commensurate with the country's financial resources. Only by doing within its capabilities can education and economic construction be guaranteed. The career develops continuously and commensurately [25]. The development of education beyond the country's financial resources will not only hinder the development of education, but also be detrimental to the entire economic construction. But on the other hand, we should see the conditions allowed by financial resources. Under the circumstances, the increase in education expenditure will play a positive role in promoting the long-term growth in fiscal revenue. In other words, if the fiscal expenditure on education is too high and there is no funding for other aspects of construction, the economic development will be unbalanced, thus hindering the regional economic development [26].

Evidence (ii) Zhu Weiming believes that as China economic system changes to a market economy, the government's functions will also change accordingly. To adapt to it, the government's fiscal expenditure structure must be adjusted to promote rapid economic development. At present, there are many unreasonable phenomena in China fiscal expenditure structure, which have caused great obstacles to economic development [27]. Therefore, it is the current fiscal reform to grasp the contribution of fiscal expenditures, especially productive expenditures, to economic growth, and seek to optimize the realization of the expenditure structure. And an urgent task facing development. This also shows that financial education expenditure is a part of fiscal expenditure. If education expenditure is too high and destroys the structure of fiscal expenditure, it will hinder economic development.

Comparison: With the rapid economic development, the government has gradually realized the importance of education for promoting economic development. Therefore, the scale of my country's (and Shndong) fiscal education expenditure is getting bigger and bigger, but the problem of the imbalance of fiscal education expenditure structure has become increasingly prominent. China fiscal education expenditure has increased substantially since 2006 , but the proportion of education expenditure in fiscal expenditure has continued to grow slowly or even declined. At the same time, the share of fiscal education expenditure in GDP has remained above $4 \%$ since it broke $4 \%$ for the first time in 2012 , but it is still low compared with developed countries. The main reason is that my country (and Shandong) has long been centered on economic construction. In order to pursue higher performance, the government has invested more fiscal expenditures in productive and industrial industries. However, the investment in the education industry that has been effective for a long time is seriously insufficient. China fiscal expenditure on education increased from 1,588,650 million yuan in 2000 to $1,649.733$ billion yuan in 2011, with an average annual growth rate of $17.02 \% .^{2}$ It can be seen that fiscal education expenditure has been increasing at a relatively high rate along with GDP growth. At the same time, China fiscal education expenditure accounted for more than $4 \%$ of GDP for 8 consecutive years starting in 2012, reaching the basic level of world education [28]. Judging from this basic situation, there is big room for improvement in the proportion of current fiscal education expenditure. Therefore, increasing fiscal expenditures on education will not affect the structure of fiscal expenditures for China. Second, after analyzing the data of Shandong Province, the results show that the increase in fiscal education expenditure has promoted economic development, so fiscal education expenditure has a promoting effect on economic development. Combining multiple evidences, scholars have shown that educational development and economic development are synchronized. Research shows that increasing fiscal expenditures on education is conducive to promoting economic development. The third point is that there is no direct evidence in the evidence of $\mathrm{H} 0$ and other documents that investment in education will directly hinder economic development. These evidences are more likely to hinder economic development when excessive fiscal investment in education leads to an imbalance in fiscal expenditure structure. However, from the current situation of China's education investment given in 
this paragraph, China's fiscal education expenditure has just reached the world's basic level. This means that the current increase in financial investment in education in Shandong Province will not hinder economic development. Therefore, the $\mathrm{H} 1$ assumption is valid.

\section{Conclusions and Recommendations}

\subsection{Conclusions}

(i) By including the per capita scientific expenses and the per capita total investment in fixed assets of the whole society, this paper shows that there is a long-term equilibrium relationship between per capita fiscal education expenditure and per capita GRDP. That is, there is a long-term equilibrium relationship between fiscal education expenditure and economic growth.

(ii) By including the per capita scientific expenses and the per capita total investment in fixed assets of the whole society, the error correction model established in this paper shows that per capita financial education expenditure has a positive effect on per capita GRDP. That is, fiscal education expenditure promotes economic growth.

\subsection{Recommendations}

(i) General Secretary Xi Jinping pointed out: "Building an educational country is a basic project for the great rejuvenation of the Chinese nation" and "accelerating the modernization of education and building an educational country" [29]. Liu Jiayi, secretary of the Provincial Party Committee, emphasized at the provincial education conference: "Shandong must accelerate the transformation from a major education province to a strong education province if it is to achieve a strategic change from large to strong and build a modern and powerful province in the new era [30]. The top of the pyramid of the education system is the overall cornerstone of the country's prosperity and an important indicator of its development potential. Now, how to further strengthen the foundation, improve quality in higher education, and respond to the situation is a heavy responsibility and a great mission. To further develop economic construction in Shandong Province, it is necessary to attach importance to education and investment in education in terms of concepts, and to place education development in an important position.

(ii) China's economic growth has surpassed that of developed countries in recent decades, and the advantage of latecomer has played a decisive role. There are three factors that affect short-term fluctuations: investment, consumption, and import and export. The factors that determine long-term economic growth must be viewed from the supply side. Therefore, the so-called troika of economic growth in traditional economics - investment, consumption, and import and export, only affects economic fluctuations, while the troika of long-term economic growth involves technological progress, investment, and education. As one of the troikas, education is positive role in promoting growth of economic.
And because Shandong's fiscal education expenditure has not reached the world average level, Shandong Province should increase the proportion of fiscal education expenditure.

(iii) If the fiscal expenditure structure is unbalanced, excessive education expenditure will hinder economic development [31]. Therefore, attention should also be paid to the optimization of fiscal expenditure structure. The government will increase investment in education in backward areas in the province, take up the funds required for free education in backward areas, and increase public funds guarantee funds and school building maintenance and renovation funds. Ensure that teachers' salaries are not in arrears and stabilize the teaching team. The government should shoulder the wages of faculty and staff for compulsory education in rural areas and establish a unified wage system, which will be directly distributed to faculty and staff through banks, credit unions or post offices by the central treasury, and the provincial treasury will be responsible for subsidies other than wages. Finance should increase the investment in college education funds, solve the serious shortage of college teaching resources as soon as possible, and ensure the improvement of teaching quality. Secondary normal education trains primary school teachers. The reduction of financial expenditure will inevitably lead to a decline in the quality of primary school teachers, which will affect the implementation of China Nine General Program and the improvement of primary school teaching quality. If it continues to deteriorate, it will inevitably restrict the improvement of residents' quality. Expenditure should focus on the investment in secondary normal education. If secondary education can be included in the scope of free education, it will be more conducive to the development of secondary normal education in our country, achieve the goal of education equity, and promote economic development in the future.

(IV) The legalization of education investment is a solid backing to effectively ensure financial education investment. Therefore, Shandong Province should strengthen the construction of the education investment law, stipulate the investment standards and responsibilities of all levels of government for various types of education, and what consequences should be borne if violated, etc. Standardize education investment and legalize various regulations. Second, it is necessary to increase the share of education finance in government fiscal expenditure. Indicators of education investment in various countries are based on the proportion of fiscal education expenditure in GDP. Therefore, if you want to enhance the status of education investment in national development, you must Legalize it and, through a gradual increase in the speed, realize as soon as possible the promise of China fiscal education expenditure as a proportion of $4+\%$ of the GDP.

(V) Finally, the main sources of fiscal education expenditures are currently central allocations and local finances. In order to reduce the fiscal deficit and ease government pressure, Shandong Province should broaden the channels for raising education investment. Funds can be raised through legal private fundraising and charitable donations 
from entrepreneurs. At the same time, a sound method of fund raising, supervision and use shall be established. Follow-up to improve the evaluation system of fund use efficiency, so that education funds flow to places where they are more needed.

\section{References}

[1] Xi Jinping. 19th National Congress of the Communist Party of China [C]. Beijing, 2017.

[2] Shandong Provincial Bureu of Statistics. Shandong Statistical Yearbook [M]. Shandong: China Statistics Press, 2018.

[3] Shen Guoyun. Empirical Analysis of Financial Education Investment and Economic Growth in Jiangsu Province [J]. Cooperative Economics \& Science, 2020, 000 (002): 147-153.

[4] Zhu Jian, Liu Yiqing, Chen Pan. Research on the Influence of Educational Financial Expenditure on Economic Growth in Hunan Province $[\mathrm{J}]$. Forum on Contemporary Education, 2020 .

[5] Hui Letian, Zhai Yang, Zhang Xiaoxia. Research on the Effect of Educational Financial Expenditment on Regional Economic Growth in Yunnan Province [J]. New Western China, 2020, No. 511 (12): 27-29.

[6] Ma Shuanyou. Public Education Expenditure and Economic Growth -- Estimation of the Optimal Scale of Fiscal Education Expenditure in China [J]. Social Scientist, 2002 (2).

[7] Wang Yancao. An Empirical Analysis of the Relationship between Education and Economic Growth in China [J]. Economic Research Guide, 2007 (8): 15-18.

[8] Zhang Zhinan. Education Finance, Social Investment and Economic Growth -- Also on the Leading Effect of Education Finance [J]. Local Finance Research, 2020, No. 183 (01): $87-94+102$.

[9] CNKI (China National Knowledge Infrastructure) [EB/OL]. https://oversea.cnki.net/index/, 2020-12-24.

[10] Baidu Scholar. [EB/OL]. https://xueshu.baidu.com/, 2021-01-05.

[11] Li zinai, Pan wenqing. Econometrics - the second edition [M]. Higher Education Press, 2005.

[12] Phillips P C B, Perron P. Testing for a unit root in time series regression [J]. Biometrika, 1988.

[13] Shin P Y. Testing for unit roots in heterogeneous panels [J]. Journal of Econometrics, 2003.

[14] Li zinai. Econometrics: Methods and Applications [M]. Tsinghua University Press, 1992.

[15] Bai Xuemei, Zhao Songshan. Co-integration and Error Correction Model [J]. Journal of Quantitative and Technical Economics, 1998, 015 (008): 39-42.

[16] Sun He, Yu Rongzhen, Wang Ruijie. Long-term Equilibrium Relationship between Education and Economic Growth: A
Case Study of Yunnan Province [J]. Journal of Yunnan Agricultural University, 2007 (02): 133-137.

[17] Wang Yuhong. An Empirical Study on the Relationship between Economic Growth and Higher Education Development in Jiangxi Province [D].

[18] Jiang Minghhui, Ren Yanyan. An Empirical Study on the Relationship between Educational Investment and Economic Growth in Shandong Province (1997-2004) [J]. Shandong Economy, 2006, 22 (6): 125-125.

[19] David Romer. Advanced Macroeconomics [M]. McGrw-Hill Education, 2014.

[20] Bai Tao, Cultural Capital and Economic Development: Theoretical Analysis and Empirical Research [D]. Fudan University, 2013.

[21] Gan Lunzhi. Research on Education and Economic Growth [D]. Southwestern University of Finance and Economics, 2008.

[22] Ye Maolin. Research on the Relationship between Education and Economic Growth [J]. Journal of Quantitative and Technical Economics, 2002 (09): 11-14.

[23] Xu Yingming. The Significance of the Little Picture Work from the Current Situation of Primary and Secondary Education in China [J]. Library Science Research, 1990 (04): 84-88.

[24] Liu Ya-qiang. The Role of Human Capital and the Function of Education in Economic Development [J]. Coastal Enterprises and Technology, 2006 (2): 223-224.

[25] Li Yining. On the Role of Education in Economic Growth [J]. China Social Sciences, 1981.

[26] Li Yining. Research on Educational Economics [M]. Shanghai People's Publishing House, 1988.

[27] Zhu Weiming. Empirical Research on the Influence of China's Fiscal Expenditure Structure on Economic Growth [D]. Northwest Normal University.

[28] Ministry of Education. China's education expenditure accounted for more than $4 \%$ of GDP for 8 consecutive years $[\mathrm{EB} / \mathrm{OL}]$.

https://baijiahao.baidu.com/s?id=1684864283334403056\&wfr $=$ spider \&for $=$ pc, $2020-12-01$.

[29] China New. Learn from General Secretary Xi Jinping's important remarks on building a strong country in education [EB/OL]. https://www.chinanews.com/11/2019/03-11/8776997.shtml, 2019-03-11.

[30] Shandong Provincial Department of Education. Shandong education conference held: comprehensively enhance the comprehensive strength of education to speed up the construction of a modern education strong province [C]. Shandong, 2018.

[31] Hena. Research on Imbalance of Financial Education Expenditure in China [D]. Northeast Normal University. 